\title{
Histocompatibility antigens in asthma: population and family studies
}

\author{
C W G TURTON, ${ }^{1}$ L MORRIS, ${ }^{2}$ J A BUCKINGHAM, ${ }^{3}$ S D LAWLER, ${ }^{2}$ \\ AND M TURNER-WARWICK ${ }^{1}$
}

From the Departments of Medicine (Thoracic Medicine $)^{1}$ and Clinical Immunology, ${ }^{2}$ Cardiothoracic
Institute, Brompton Hospital, London SW3 $6 H P$, and the Department of Cytogenetics and
Immunogenetics, ${ }^{3}$ Institute of Cancer Research and Royal Marsden Hospital, London SW3, UK

ABSTRACT One hundred and twenty-two patients with intrinsic asthma, extrinsic atopic asthma, or asthma with allergic bronchopulmonary aspergillosis were tissue typed for the HLA A, B, and C loci. No associations were found with any of the clinical groups, or with serum total IgE concentrations. Sixty-eight members of 10 families where more than one member was affected by asthma were studied. The segregation of haplotypes in siblings of the propositi who were or were not affected by asthma did not differ from the predicted segregation, and there were no differences when atopy or serum total IgE were considered. No biologically important association between HLA and asthma has been shown.

The possibility of increasing understanding of the mechanisms by which inherited factors influence disease has stimulated the study of human leukocyte antigens (HLA). HLA is controlled by genes within the major histocompatibility complex, which is associated with other aspects of immune response, some complement components, and susceptibility to certain diseases (Svejgaard et al, 1975).

Asthma is a multifactorial disease, and the influence of genetic factors is not understood. Environmental factors interact with atopy, which itself is influenced genetically (Pepys, 1973; Marsh et al, 1974). The pattern of inheritance of asthma may be explained best on a multigenic basis (Sibbald and Turner-Warwick, 1979).

The results of previous studies on HLA in atopy and asthma are conflicting. Weak associations with various antigens have been reported in atopic dermatitis (Weck, 1977) and a haplotype association was found in a family study (Scholz et al, 1977). An increase in HLA B8 was suggested by Thorsby et al (1971) but not confirmed by Rachelefsky et al (1976). Other antigens have also been implicated (Brostoff, 1976). The problems of case selection may have contributed to the conflicting results. Interest was created by reports of HLA associations within families with hypersensitivity to purified ragweed antigens (Levine et al, 1972; Blumenthal et al, 1974), but these results have been disputed (Black et al, 1976). It has also been suggested that HLA antigens may be associated with IgE-mediated sensitivity to specific ragweed antigens (Marsh et al, 1973).

We have sought HLA associations in carefully defined populations with intrinsic asthma, extrinsic atopic asthma, and allergic bronchopulmonary aspergillosis, and haplotype associations with asthma and atopy in family studies.

\section{Methods}

POPULATION STUDIES

Selection-White patients attending the Brompton Hospital with asthma, defined as airways obstruction varying either spontaneously or with treatment over short periods, were selected. Those satisfying the MRC criteria for chronic bronchitis were excluded. The groups were defined by the following criteria:

Intrinsic asthma-41 patients: (a) no history of allergic factors provoking asthma, (b) no history of allergic rhinitis or eczema, $(c)$ no positive reactions 0 to skin prick testing with 23 common allergens.

Extrinsic atopic asthma-40 patients: (a) $\stackrel{\mathcal{D}}{+}$ definite history of asthma provoked by allergic $\underset{T}{T}$ factors, $(b)$ at least three positive reactions to skin prick testing with 23 common allergens.

Allergic bronchopulmonary aspergillosis $\mathbb{D}$ $(A B P A)-41$ patients: $(a)$ positive prick skin test 
to Aspergillus fumigatus antigen, Beneard $5 \% \mathrm{w} / \mathrm{v}$ (only those with at least three positive skin prick tests to 23 common allergens were selected so that the group is comparable to the extrinsic atopic group with regard to degree of atopy), (b) demonstration of circulating precipitating antibody to $A$ fumigatus, (c) radiographic abnormality of one of three types-transient pulmonary infiltrates, fixed pulmonary shadows, or bronchiectasis.

Many of the ABPA patients had further supporting evidence for the diagnosis-for example, positive five-hour reactions to aspergillus skin testing or positive sputum culture of Aspergillus species. Ten had bronchiectasis. The population has been described (Malo et al, 1977).

\section{CLINICAL ASSESSMENT}

Patients completed a standard clinic questionnaire of details of their respiratory symptoms and past history and were examined. Prick skin testing was done with the following allergens: Alternaria, A fumigatus, $A$ terreus, Cladosporium herbarum, Meruleus lacrimans, sporobolomyces, Candida albicans, yeast, grass, shrub, trees, milk, egg, wheat, fish, nuts, cat, dog, feathers, horse, ascaris, house dust, and Dermatophagoides farinae. The diameter of the weal at ten minutes was measured and reactions were considered positive if they measured more than $2 \mathrm{~mm}$ providing the control was negative.

A standard $6 \mathrm{ft}$ posteroanterior chest radiograph was taken. Peak expiratory flow rates, forced vital capacity, and forced expired volume in one second were measured by Wright peak flow meter and Vitalograph before and after inhalation of salbutamol by aerosol. Venous blood was taken for serum separation and HLA typing.

Details of sex, age at assessment, age at onset of asthma, presence of allergic asthma-provoking factors, allergic rhinitis or eczema or both, results of skin prick testing, and radiographic abnormality for the three groups are shown in table 1.

\section{FAMILY STUDIES}

Sixty-eight members of white families were investigated. The families were selected if the index case (propositus) had at least one other sibling with asthma who was accessible for investigation. As many other first-degree relatives as possible were assessed fully as described above. The other family members completed the asthma questionaire; were skin prick tested to house dust mite, grass pollen, cat fur, dog fur, $A$ fumigatus, and control; and recorded peak flow measurements before and after inhaled salbutamol.
Table 1 Asthma population studies-details of subgroups

\begin{tabular}{|c|c|c|c|}
\hline Asthma type & Intrinsic & Extrinsic & $A B P A$ \\
\hline No in group & (41) & (40) & (41) \\
\hline $\operatorname{Sex}(F: M)$ & $21: 20$ & $21: 19$ & $22: 19$ \\
\hline \multirow{2}{*}{$\begin{array}{l}\text { Assessment age -Mea } \\
\text { (yr) }\end{array}$} & $54 \cdot 4$ & $23 \cdot 2$ & $41 \cdot 8$ \\
\hline & 28-79 & $9-53$ & $18-66$ \\
\hline \multirow{2}{*}{$\begin{array}{ll}\text { Onset age } & \text { - Mean } \\
\text { (yr) } & \text {-Range }\end{array}$} & $42 \cdot 0$ & $4 \cdot 2$ & $9 \cdot 9$ \\
\hline & $1-69$ & $0-16$ & $0-45$ \\
\hline Allergic provoking factors & None - & All & 22 \\
\hline \multirow{2}{*}{$\begin{array}{l}\text { Allergic rhinitis/eczema } \\
\text { No positive skin tests-Mean }\end{array}$} & None & & \\
\hline & 0 & $9 \cdot 5$ & $7 \cdot 9$ \\
\hline (Total 23) -Range & 0 & $5-21$ & $3-17$ \\
\hline \multicolumn{4}{|l|}{ Radiographic abnormality- } \\
\hline \multirow{2}{*}{$\left.\begin{array}{l}\text { Transient shadows } \\
+ \text { Fixed shadows } \\
\text { Pronchiectasis }\end{array}\right\}$} & & & 13 \\
\hline & None & None & \\
\hline $\begin{array}{l}\text { - Mean } \\
\text {-Range }\end{array}$ & $\begin{array}{l}212 \\
8-1750\end{array}$ & $\begin{array}{l}1348 \\
56-4700\end{array}$ & $\begin{array}{l}4058 \\
52-23500\end{array}$ \\
\hline
\end{tabular}

ASPERGILLUS PRECIPITINS

The presence of serum precipitins to Aspergillus and Candida species were detected by a double diffusion technique (Longbottom and Pepys, 1964).

\section{SERUM TOTAL IgE}

Total IgE was measured by a Sepharose particle radioimmunosorbent test (SPRIST) (Cromwell et al, 1979).

HLA TYPING

Ten $\mathrm{ml}$ of heparinised blood was taken. Lymphocytes were separated over Ficoll-Triosil and stored in liquid nitrogen until HLA typed. A standard two-stage microlymphocytotoxicity method was used (Kissmeyer-Nielsen and Kierbye, 1967). To each 2000 lymphocytes $1 \mu l$ of antiserum and $5 \mu \mathrm{l}$ of complement were added. Dead and living cells were scored by Trypan blue exclusion; 115 sera were used, obtained from screening of local pregnant women and the NIH bank. The sera conformed to the international standards of the 7th Histocompatibility Workshop, Oxford, 1977. These sera defined 14 antigens of the A locus, 17 antigens of the B locus, BW4, and BW6, and 5 loci of the $\mathrm{C}$ locus. All patients were $\mathrm{ABO}$ and rhesus-blood grouped.

ANALYSIS OF HLA POPULATION STUDIES

The frequency of the HLA antigens in each group was compared with the frequencies in other groups and with 167 healthy hospital and laboratory workers using the Chi-square test with Yates correction.

Probability values of $0.05-0.001$ should be considered critically because of the large number of comparisons made unless a previous study has suggested a particular antigen to be of a priori 
Table $2 H L A$ haplotypes in asthma families

\begin{tabular}{|c|c|c|c|c|c|c|c|c|c|c|c|c|c|c|c|c|c|c|c|c|c|}
\hline \multirow{3}{*}{\multicolumn{2}{|c|}{$\begin{array}{l}\text { Family } \\
\text { no }\end{array}$}} & \multicolumn{6}{|c|}{ Paternal haplotypes } & \multicolumn{6}{|c|}{ Maternal haplotypes } & \multirow{3}{*}{$\begin{array}{l}\text { Haplotype } \\
\text { propositus }\end{array}$} & \multirow{3}{*}{$\begin{array}{l}\text { Other } \\
\text { associated } \\
\text { disease } \\
\text { haplotype }\end{array}$} & \multicolumn{3}{|c|}{ Affected } & \multicolumn{3}{|c|}{ Unaffected $\overline{\mathrm{O}}$} \\
\hline & & \multicolumn{3}{|c|}{ " $a$ " } & \multicolumn{3}{|l|}{ "b" } & \multicolumn{3}{|l|}{ "c" } & \multicolumn{3}{|l|}{ "d" } & & & \multirow{2}{*}{2} & \multirow[t]{2}{*}{1} & \multirow[t]{2}{*}{0} & \multirow[t]{2}{*}{2} & \multirow[t]{2}{*}{1} & \multirow{2}{*}{$0 \frac{\text { (D) }}{\text { อ }}$} \\
\hline & & $A$ & $B$ & C & $A$ & $\boldsymbol{B}$ & $C$ & $A$ & $\boldsymbol{B}$ & $C$ & $A$ & $\boldsymbol{B}$ & $C$ & & & & & & & & \\
\hline 1 & & 2 & 7 & & W19 & 13 & & 28 & 5 & & 3 & 40 & W2 & $a / c$ & $\mathrm{~b} / \mathrm{d}$ & & & 1 & & 1 & \\
\hline 2 & & 2 & 27 & W2 & W29 & W44 & & 1 & 8 & & 2 & W44 & $\sqrt{12}$ & $a / c$ & b/d & & & 2 & & 2 & \\
\hline 3 & & 2 & W35 & W4 & 2 & W44 & W4 & & 7 & & $\overline{1}$ & 13 & & $a / c$ & b & & 1 & & 2 & 1 & \\
\hline 4 & II & 26 & W38 & & 3 & 5 & & W19 & 27 & W2 & W19 & 27 & & $a / c$ & - & 1 & & & 2 & & \\
\hline & III & 1 & W35 & & 1 & 17 & & W19 & 27 & & 26 & W38 & & $\mathrm{b} / \mathrm{d}$ & - & & & & & & \\
\hline 5 & & 1 & 5 & & 2 & 13 & & 26 & W35 & & W26 & W22 & & $a / c$ & $b / d$ & 1 & & 1 & & & $1=$ \\
\hline 6 & & 2 & W44 & W5 & 2 & 7 & & 1 & 8 & & & 7 & & $a / c$ & d & 1 & 1 & & & & \\
\hline \multirow[t]{2}{*}{7} & I & 3 & 15 & W3 & & $?$ & & 3 & 8 & & W31 & 15 & & $a / c$ & - & & & & \multirow{2}{*}{\multicolumn{2}{|c|}{1}} & \\
\hline & II & 2 & & & W24 & 7 & & 3 & 8 & & 3 & 15 & W3 & $\mathbf{b}^{\prime} / \mathbf{c}$ & $d^{\prime}$ & & 1 & & & & \\
\hline 8 & & 2 & W44 & & 1 & W44 & & W24 & W35 & & 1 & 37 & & $a / c$ & d & 1 & 2 & & & 1 & \\
\hline \multirow[t]{2}{*}{9} & I & 3 & W35 & & 11 & 40 & & & 40 & & 1 & 40 & & $\mathrm{~b} / \mathrm{c}$ & - & 1 & & & & 2 & \\
\hline & II & 3 & W35 & & 1 & 40 & & W24 & W38 & & W32 & 40 & W2 & $a / c$ & d & & & 1 & & 2 & \\
\hline \multirow[t]{3}{*}{10} & I & 1 & 8 & & 11 & 7 & & W23 & 7 & & 2 & W44 & & $a / c^{\prime}$ & - & 1 & & & & & \\
\hline & II & 1 & 8 & & 11 & 7 & & 2 & 14 & & 2 & W39 & & $a / c$ & $\mathbf{b} / \mathbf{d}$ & 2 & 1 & 1 & & 1 & \\
\hline & & & & & & & & & & & & & & & Total & 8 & 6 & 6 & 2 & 11 & \\
\hline
\end{tabular}

interest. P values may be "corrected" by multiplying by the number of comparisons made (Vladutiu and Rose, 1974). Relative risks were calculated to give an index of frequency of disease in those subjects carrying an antigen in relation to those not.

\section{ANALYSIS OF HLA FAMILY STUDIES}

The principle of the analysis is the segregation of HLA haplotypes in asthmatic, atopic, and unaffected relatives.

The figure shows the family pedigrees. The haplotypes for each family were deduced by inspecting the pedigree to see which antigens at different loci occurred together consistently. Paternal haplotypes are represented by letters " $a$ " and " $b$ " and maternal haplotypes by " $c$ " and "d." These letters were assigned so that the haplotypes of the propositus were "a/c." The antigens constituting each haplotype in the families can be seen in table 2 , columns two to five. Different generations within a family must be considered separately because a child must inherit one or other haplotype from a parent, and this gives the measures a degree of dependence. The "secondary" generation parents are represented by " $a$ ' $/ b^{\prime}$ " and " $c$ ' $/ d$ '." Thus a single haplotype may be represented by two codes, for example $b / c^{\prime}$, so that the generations can be considered separately. The propositus of each family is indicated by an arrow. The index case for the secondary generations is the parent or child of the propositus unless that individual is unaffected. The eldest appropriate member of the secondary generation is then taken as the index case.
For the asthmatic propositi, the number of asthmatic and non-asthmatic siblings sharing both, $\vec{\oplus}$ one, or neither haplotype are tabulated separately in table 2. The overall distribution for the degree of haplotype sharing, or segregation, for all theo families is found by summing those sharing both, one, and neither haplotype. The predicted segrega-o tion is calculated taking account of generationso where not all of the haplotypes could be ascer- $\Omega$ tained. The observed and predicted distributions $\overrightarrow{\vec{\sigma}}$ were compared using the distribution Chi-square 3 test (table 3).

Similar analyses were done taking atopic propositi and considering atopic and non-atopic relatives, and taking propositi with raised serumo total IgE concentrations and considering relativesx with normal and raised IgE.

\section{Results}

HLA POPULATION STUDIES

The HLA frequencies in general did not differ significantly when the whole asthma group or the asthma subgroups were compared with controls s or other subgroups. The exceptions are shown in table 4 . The frequencies, probability values, and relative risks are shown for those comparisons that $\omega$ were significant before correction. None of the probabilities is significant after correction for the number of comparisons made. Full details of allळ HLA frequencies for the various groups are avail-:able on request.

HLA FAMILY STUDIES

In table 3 the families are considered together $\stackrel{\mathbb{Q}}{2}$ and compared with the segregation predicted for $a$ 

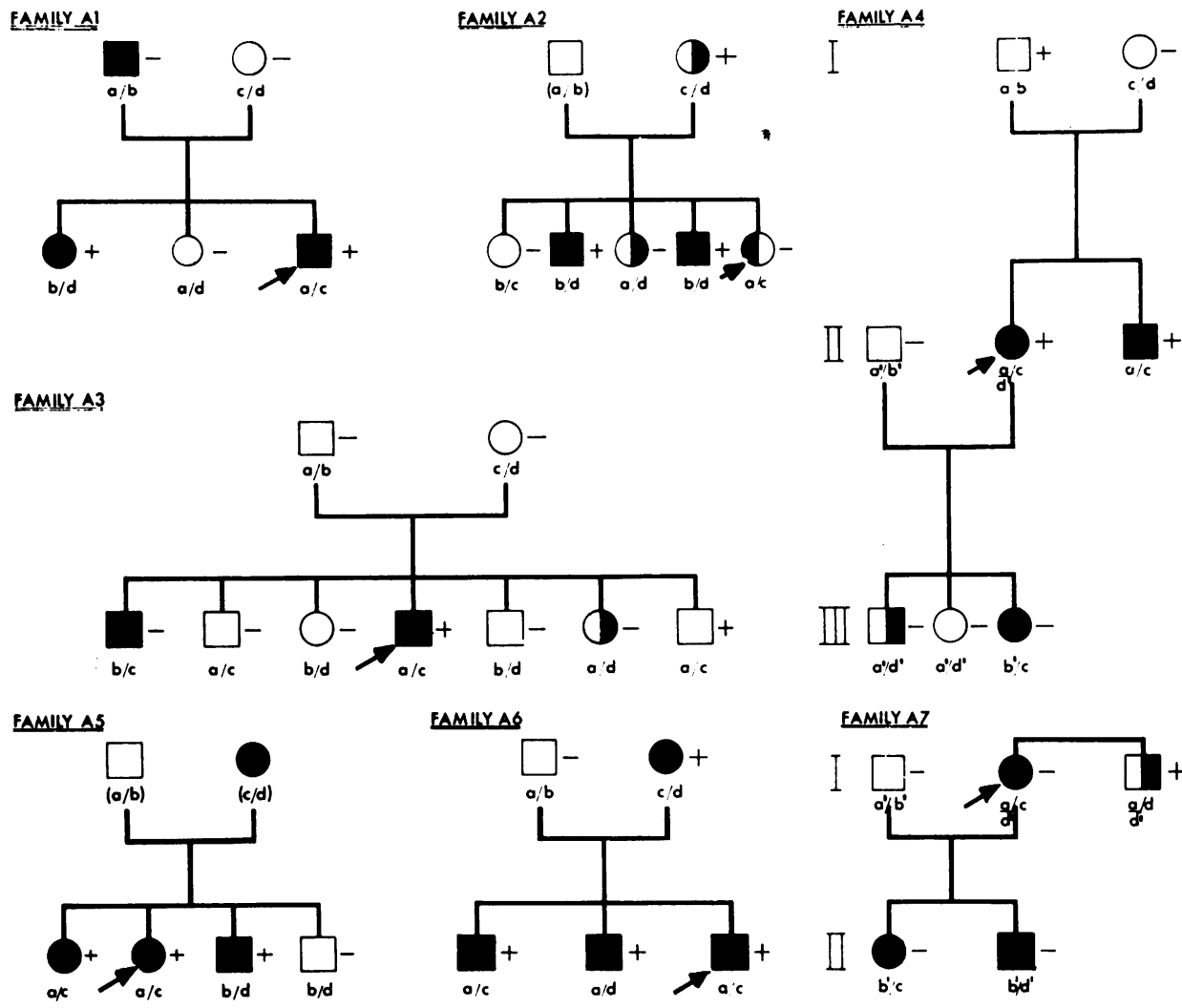

EAMIIYAG

EMMUY A
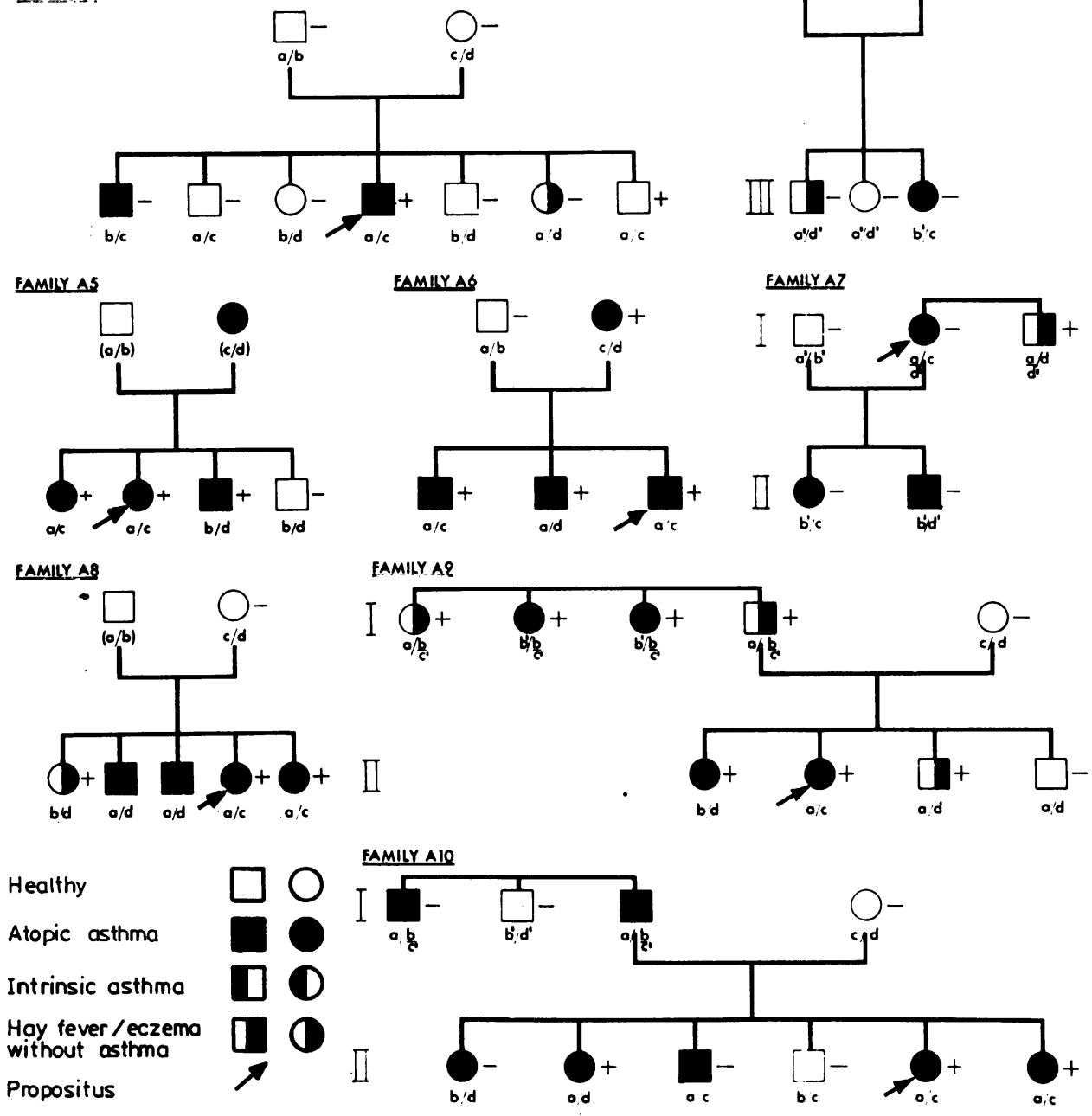

HLA haplotypes are represented by small letters and antigens are identified fully in table 2 (see text). + indicates raised serum total IgE and - normal total IgE. Parentheses () indicate that subject was not available and haplotypes have where possible been deducted from segregation in rest of family, or assumed. 
Table 3 Haplotype sharing in asthmatic families

\begin{tabular}{|c|c|c|c|c|c|c|c|c|c|}
\hline \multirow[t]{2}{*}{ Propositus } & \multirow[t]{2}{*}{ Group } & & \multirow[t]{2}{*}{ Total } & \multicolumn{3}{|c|}{ Haplotypes shared } & \multirow{2}{*}{$\begin{array}{l}\text { Distribution } \\
X^{2}\end{array}$} & \multirow[t]{2}{*}{$\mathbf{P}$} & \\
\hline & & & & 2 & 1 & 0 & & & \\
\hline Asthmatic & Asthmatic siblings & $\begin{array}{l}\text { Observed } \\
\text { Predicted }\end{array}$ & 20 & $\begin{array}{l}8 \\
5\end{array}$ & $\begin{array}{c}6 \\
10 \cdot 25\end{array}$ & $\begin{array}{l}6 \\
4 \cdot 75\end{array}$ & 3.91 & $\begin{array}{l}\text { NS } \\
>0.1\end{array}$ & $<0.5$ \\
\hline Asthmatic & Non-asthmatic siblings & $\begin{array}{l}\text { Observed } \\
\text { Predicted }\end{array}$ & 19 & $\begin{array}{l}2 \\
4 \cdot 75\end{array}$ & $\begin{array}{l}11 \\
10\end{array}$ & $\begin{array}{l}6 \\
4 \cdot 25\end{array}$ & $2 \cdot 88$ & $\begin{array}{l}\text { NS } \\
>0.1\end{array}$ & $<0.5$ \\
\hline Atopic & Atopic siblings & $\begin{array}{l}\text { Observed } \\
\text { Predicted }\end{array}$ & 27 & $\begin{array}{l}9 \\
6 \cdot 75\end{array}$ & $\begin{array}{l}12 \\
14 \cdot 25\end{array}$ & $\begin{array}{l}6 \\
6\end{array}$ & $1 \cdot 11$ & $\begin{array}{l}\text { NS } \\
>0.5\end{array}$ & $<0.9$ \\
\hline Atopic & Non-atopic sibl:ngs & $\begin{array}{l}\text { Observed } \\
\text { Predicted }\end{array}$ & 12 & $\begin{array}{l}3 \\
3\end{array}$ & $\begin{array}{l}4 \\
6\end{array}$ & $3^{5}$ & $2 \cdot 0$ & $\begin{array}{l}\mathrm{NS} \\
>0.1\end{array}$ & $<0.5$ \\
\hline$\uparrow \operatorname{IgE}$ & $\uparrow$ IgE siblings & $\begin{array}{l}\text { Observed } \\
\text { Predicted }\end{array}$ & 17 & $\begin{array}{l}7 \\
4 \cdot 25 \\
\end{array}$ & $\begin{array}{l}7 \\
9 \cdot 25\end{array}$ & $\begin{array}{l}3 \\
3 \cdot 5\end{array}$ & $2 \cdot 40$ & $\begin{array}{l}\text { NS } \\
>0.1 \\
\end{array}$ & $<0.5$ \\
\hline$\uparrow \operatorname{IgE}$ & Normal IgE siblings & $\begin{array}{l}\text { Observed } \\
\text { Predicted }\end{array}$ & 15 & $\begin{array}{l}3 \\
3 \cdot 75\end{array}$ & $\begin{array}{l}8 \\
7 \cdot 75\end{array}$ & $\begin{array}{l}4 \\
3 \cdot 5\end{array}$ & 0.22 & $\begin{array}{l}\text { NS } \\
>0.5\end{array}$ & $<0.9$ \\
\hline
\end{tabular}

null hypothesis of no haplotype association, having regard for generations where not all of the haplotypes have been ascertained. The segregation does not differ significantly from that predicted. Five of the ten families are not consistent with a single postulated asthma associated haplotype, and in families of this size the consistency in the other families could be due to chance.

The analysis was repeated in a similar way for the atopic and non-atopic siblings of atopic index cases, and siblings with normal and raised total IgE concentrations of index cases with raised total IgE concentrations. There are no significant differences between the observed and predicted segregations (table 3).

Table 4 Differences in HLA frequencies within asthma subgroups and between controls

\begin{tabular}{lllllll}
\hline $\begin{array}{l}\text { Groups } \\
\text { compared }\end{array}$ & HLA & \multicolumn{2}{c}{ Frequencies } & P & Relative \\
\hline Intrinsic/control & B8 & 41 & 23 & $<0.05$ & 2.7 \\
Extrinsic/control & B15 & 25 & 8 & $<0.02$ & 3.6 \\
ABPA/control & B7 & 15 & 32 & $<0.05$ & 0.36 \\
Normal IgE/high IgE & A2 & 77 & 49 & $<0.01$ & 3.5 \\
\hline
\end{tabular}

$P$ values are uncorrected for the number of comparisons made.

\section{Discussion}

Care has been taken to define populations of asthmatics that are clinically either definitely extrinsic atopic or intrinsic. ABPA is of particular immunological interest, offering an opportunity to investigate response to a well-defined antigen, and is of clinical importance as a cause of irreversible airways obstruction. The results of the population studies reported here suggest that there is no real association between asthma and the HLA A, $\mathbf{B}$, or $\mathbf{C}$ loci. There is no convincing a priori interest in published reports for the antigens where differences were found, and none of the differences were significant after correction for the number of comparisons made. The work of Thorsby et al (1971) has been cited as showing an increased frequency of $\mathbf{A} 1 / \mathrm{B} 8$ in asthmatic children, but the figures were not significant at the $5 \%$ level even before consideration of the number of comparisons made. The lack of association with serum total IgE concentrations is consistent with published reports.

Brostoff et al (1976) reported an increased frequency of BW6 in intrinsic asthma and suggested that this was evidence for a recessive mode of inheritance. Their study can be criticised in that the numbers were small and included patients with chronic bronchitis. No correction for the number of comparisons was made. The justification of conclusions about patterns of inheritance without family studies is doubtful. Our results show no evidence for this association even when only those patients resistant to treatment with sodium cromoglycate are considered.

Turner et al (1977) reported differing frequencies of common HLA antigen combinations in some atopic syndromes. A1 with B8 was increased in eczema associated with hay fever or asthma, but not in eczema, hay fever, or asthma alone. A1/B8 was considered of a priori interest after Thorsby et al (1971), so no correction for the number of comparisons was made. Our results show a trend for this combination to occur more often in the presence of eczema, but this was not significant.

Family studies can help in defining weak HLA disease associations and have other advantages over population studies. Genetic and environmental differences within families are more limited than in the general population. HLA disease associations should be found if they exist as it would be expected that genetic influence in multi- 
factorial disease would be particularly important in families where several siblings are affected. When associations are found conclusions can be made about the type to gene inheritance, penetrance, and linkage.

Family studies also have their problems. Suitable families are unusual, and important members may be inaccessible so numbers tend to be small. All the haplotypes may not be identified if only one generation is available. Allowance then must be made when the predicted segregation is calculated, or it is assumed that all four haplotypes are different. Illegitimacy complicates analysis and supporting evidence of paternity from consistent $\mathrm{ABO}$ and rhesus blood group inheritance is important. There is a degree of dependence of the measures, and care must be taken in combining analysis of different generations. Assumptions are made when considering unaffected relatives about disease that has not been expressed clinically or is expressed subsequently. Haplotype segregaation in unaffected members will be altered only if there is an association and the gene penetrance is high.

The reports of family studies suggesting linkage between HLA haplotypes and hypersensitivity to ragweed antigens created wide interest (Levine et al, 1972; Blumenthal et al, 1974). Black et al (1976) was unable to confirm these findings in a study of a larger number of small families. Wagatsuma et al (1976) reported an association between HLA haplotypes and asthma but the way in which different generations were analysed together can be criticised.

The family studies reported here show no significant HLA haplotype association with asthma or atopy. Five of the ten families are not consistent with a postulated asthma associated haplotype. The observation that the asthma affected siblings of asthmatic propositi share both haplotypes more often than asthma unaffected siblings does not exclude the possibility of association in some families, possibly with highly specific immune response genes.

It is concluded that no associations of overall biological importance between HLA and asthma have been found. Genetic influences in asthma are very complex and study of other markers, genetic, immunological, and biochemical will be needed to elucidate the mechanisms of these influences.

We thank Professor Pepys for allowing us to study his patients and for helpful criticism, and Dr M D Lebowitz for statistical advice.
The work was supported by NIH Contract NO1HR-62935.

\section{References}

Black, P L, Marsh, D G, Jarrett, E, Delespesse, G J, and Bias, W B (1976). Family studies of association between HLA and specific immune responses to highly purified pollen allergens. Immunogenetics, 3, 349-368.

Blumenthal, M N, Amos, D B, Noreen, H, Mendell, N R, and Yunis, E J (1974). Genetic mapping of $\mathbf{l r}$ locus in man: linkage to second locus of HLA. Science, 184, 1301-1303.

Brostoff, J, Mowbray, J F, Kapoor, A, Hollowell, S J, Rudolf, M, and Saunders, K B (1976). 80\% of patients with intrinsic asthma are homozygous for HLA W6-Is intrinsic asthma a recessive disease? Lancet, 2, 872-873.

Cromwell, O, Pepys, J, Parish, W E, and Hughes, E G (1979). Specific IgE antibodies to platinum salts in sensitized workers. Clinical Allergy, 9, 109.

Kissmeyer-Nielson, F, Kierbye, K E (1967). Lymphocytotoxic Micro-technique in Histocompatibility Testing, p 381, edited by E S Curtoni, P L Mattiuz, and $\mathbf{R} \mathbf{M}$ Tosi. Munksgaard, Copenhagen.

Levine, B B, Stember, R H, and Fotino, M (1972). Ragweed hay fever: genetic control and linkage to HLA haplotypes. Science, 178, 1201-1203.

Longbottom, J L, and Pepys, J (1964). Pulmonary aspergillosis: diagnostic and immunological significance of antigens and c-substance in Aspergillis fumigatus. Journal of Pathology and Bacteriology, 88, 141-151.

Malo, J L, Hawkins, R, and Pepys, J (1977). Studies on chronic allergic bronchopulmonary aspergillosis. 1 clinical and physiological findings. Thorax, 32, 254-261.

Malo, J L, Pepys, J, and Simon, G (1977). Studies in chronic allergic bronchopulmonary aspergillosis. 2 radiological findings. Thorax, 32, 262-268.

Marsh, D G, Bias, W B, Hsu, S H, and Goodfriend, L (1973). Association of the HL-A7 cross-reacting group with a specific reaginic antibody response in allergic man. Science, 179, 691-693.

Marsh, D G, Bias, W B, and Ishizaka, K (1974). Genetic control of basal serum immunoglobulin $\mathrm{E}$ level and its effect on specific reaginic sensitivity. Proceedings of the National Academy of Science, USA, 71, 3588-3592.

Pepys, J (1973). Types of allergic reaction. Clinical Allergy, 3, 491-509.

Rachelefsky, G S, Terasaki, P I, Park, M S, Katz, R, Siegel, S, and Saito, S (1976). Strong association between B-lymphocyte group-2 specificity and asthma. Lancet, 2, 1042-1044.

Scholz, S, Ziegler, E, Wüstner, H, Braun-Falco, O, and Albert, E D (1977). HLA family studies in patients with atopic dermatitis. Monographs in Allergy, 11, 44. 
Sibbald, B, and Turner-Warwick, M (1979). Factors influencing the incidence of asthma among first degree relatives of extrinsic and intrinsic asthmatics. Thorax, 34, 332-337.

Svejgaard, A, Platz, P, Ryder, L P, Nielsen, L S, and Thomsen, M (1975). HLA and disease associations-a survey. Transplantation Reviews, 22, 3-43.

Thorsby, E, Engeset, A, and Lie, S O (1971). HLA antigens and susceptibility to disease. Tissue Antigens, 1, 147-152.

Turner, M W, Brostoff, J, Wells, R S, Stokes, C R, and Soothill J F (1977). HLA in eczema and hay fever. Clinical and Experimental Immunology, 27, 43-47.

Vladutiu, A O, and Rose, N R (1974). HLA antigens: association with disease. Immunogenetics, 1, 305- $\overrightarrow{\bar{N}}$ 318.

Wagatsuma, Y, Yakura, H, Nakayama, E, Wakisaka A, Aizawa, M, Miyata, M, Matsuyama, R, Sato $\overline{\bar{c}}$ $M$, and Itakura, $K$ (1976). Inheritance of asthma in families and its linkage to HLA haplotypes. Acta Allergolica, 31, 455-462.

Weck, A L de (1977). HLA and allergy. Monographs in Allergy, 11, 3-18.

Requests for reprints to: Dr C W G Turton Department of Medicine (Thoracic Medicine), Cardiothoracic Institute, Brompton Hospital, Fulham Road, $\rightarrow$ London SW3 6HP. 